\title{
On the problem of spatial placement of the companies engaged in emotions
}

The price of emotions changes largely. While buying the ticket to the cinema, the spectator actually buys the possibility of experiencing the emotions valuable to it during one and a half to two hours. Thus, the price of positive emotions in the Russian market of entertainment appears to be equal to 60-300 rbl./man-hour. Actually the cost of emotions is above the ticket price, which includes the risk price that the film which we intend to see will not be pleasant.

Extremely expensive emotions can be bought, for example, in a casino. A few minutes of very strong passion can cost here from ten thousand to millions of roubles. So the top limit of the price of emotions can reach $10^{8}$ roubles for a man-hour or higher.

There are whole areas of the modern market in which the emotional aspect of economic behavior initially plays a paramount role. These are the areas of manufacture and distribution of luxury goods, show-business and the so-called market of cultural values - cinema, theatre, music and so on.

Emotions of pleasure, pride and concern are mostly demanded in the markets. However, not a smaller demand exists for the emotions which can be perceived as negative - fear, uneasiness, gloating, anger. Such a version of fear as passion and such versions of anger as boldness, bravery and impudence are the basic traits of gaming. The gaming annual turnover does not give in to exact definition, but under the indirect data it is possible to assert that its scale makes more than $10^{11} \$$ a year.

The total amount of financial streams proceeding through these markets reaches an order of $10^{11}-10^{12} \$$ per year, which is comparable with such "rational” markets as oil, metals or real estate. According to a well known audit company PricewaterhouseCoopers the cumulative world turnover of show-business and mass-media in 2007 has exceeded to $1,5 \cdot 10^{12} \$$, and by 2011 will reach $2 \cdot 10^{12} \$$.

There is numerous data on the interconnection between the unconscious emotional motivations and taking administrative decisions, including those in the sphere of managing investment streams. However, up till now, emotionally-shaped aspects have not been considered enough in the models of regional economic development.

The market of emotions is out of control in terms of the harm that some emotions can cause to the consumer. The system of protection of consumer rights is not working in this market segment. As a result, the media can freely transmit pathogenic (neurotic) images.

The main type of enterprises that produce the emotions are the media. The spatial structure of the location of such enterprises is poorly investigated. However, it is obvious that 
most of the images with emotional content are produced in large cities and metropolitan areas - megapolises and megalopolises. The images contain the emotions that are characteristic for the lifestyle of people inhabiting large and mega-urban agglomerations.

Jean Bodriyard wrote: "More and more dense congestions of millions of people in the city territories, inevitably conduct their joint residing to growth of violence caused by that circumstance that in the conditions of the compelled promiscuity people as though are mutually cancelled. And it is already something opposite to social life or, on the contrary, sociality top, it is an extreme display when it starts to collapse by itself". ${ }^{1}$

It is repeatedly noted, that the lifestyle in a modern megalopolis is psychologically unhealthy. High levels of stress, plenty of destructive emotions of anger, fear and loathing - all of this is typical of the hyper-urban environment. The media are reproducing and selling in the markets of emotions the neurotic images generated by the unhealthy environment.

We have developed a special technique of the frequency content analysis for measuring the emotional essence of texts. The technique includes the following steps:

1. The lemmas designating emotional conditions are allocated;

2. To each lemma values in the conditional points, reflecting intensity of the emotion are appropriated;

3. In the investigated text calculation of the quantity of each lemma is made;

4. The resulted frequency of presence of each lemma under the formula (1) is calculated

$$
\mathrm{N}_{\mathrm{i}}=\left(\mathrm{n}_{\mathrm{i}} / \mathrm{k}\right) * 10^{6}-\mathrm{M}_{\mathrm{i}}
$$

$\mathrm{N}_{\mathrm{i}}$ - the resulted rate of $i$ lemmas;

$n_{i}$ - the quantity of words of the $i$ lemmas, found out in the investigated text

$\mathrm{k}$ - total amount of words in the investigated text (text volume)

$\mathrm{M}_{\mathrm{i}}$ - the rate of $i$ lemmas in one million words of English language (ipm) according to the frequency word book. The rate of $i$ lemmas was defined as the sum of rates of all word forms containing the given lemma;

5. The intensity of presence of each base emotion in the text under the formula (2) is calculated:

$$
\mathrm{I}_{\mathrm{j}}=\sum\left(\mathrm{N}_{\mathrm{j}, \mathrm{i}} * \mathrm{~b}_{\mathrm{j}, \mathrm{i}}\right)
$$

$I_{j}$ - the intensity of presence of $j$ emotions in the text

$\mathrm{N}_{\mathrm{j}, \mathrm{i}}$ - the resulted frequency of the $i$ lemmas, concerning $j$ emotion

$\mathrm{b}_{\mathrm{j}, \mathrm{i}}$ - the intensity of the $j$ emotion expressed by $i$ lemma.

We have studied the emotional spectrum of some media outlets in years 2007-2010. The method of the frequency content analysis was used. The method is to measure the relative frequency of lemmas, signifying the emotions of different types and varying intensity. The total input array is of about 250,000 words.

The analysis of the texts in "Rossiyskaya Gazeta" (the most popular newspaper in modern Russia) confirmed the original hypothesis. The analysis of the emotional content of the texts in "Rossiyskaya Gazeta" revealed the controversial and complex image. On the one hand, for a given image characterized by a strong sense of guilt and even remorse these emotions are experienced with joy and pride. On the other hand there is a sense of conscience associated

${ }^{1}$ Бодрийяр Ж. Город и ненависть.// Логос, М., 1997, № 9, с. 107-117. 
with fear and anxiety, which, in turn, is perceived with excitement and glee. Manifestations of the same modesty and shame are experienced as weakness and impotence. The dominant emotion is fault, the other emotions are expressed weakly.

The typical chart of presence of basic emotions in the texts published in "Rossiyskaya Gazeta” is shown in fig. 1:

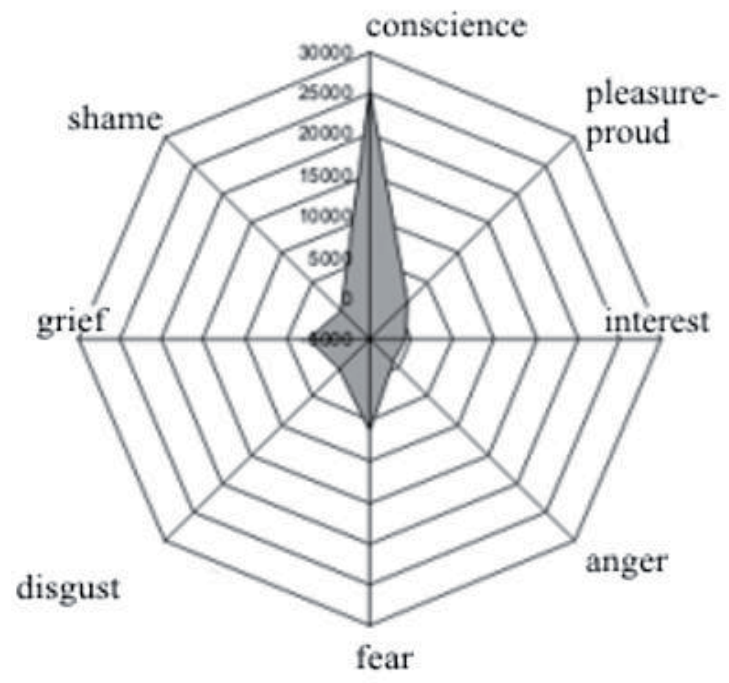

Fig. 1. The diagram of presence of basic emotions in the texts published in "Rossiyskaya Gazeta" according to the frequency content analysis

As we see in the diagram, basic emotions are present in texts non-uniformly. The emotion of "conscience" sharply prevails in this spectrum. The degree of its expressiveness conforms to the word "guilt". The lemmas appropriating opposite emotion - "fear" - and some other also are present at the quantity exceeding average.

On the contrary, the lemmas meaning "shame”, "interest” and "anger" are present at frequencies below an average. As a result the analyzed text bears poor and monotonous emotional impression.

As a whole, an emotional condition which bears this text we can characterize as sad, disturbing and loaded with strong feeling of guilt, but thus uninteresting and shameless. Because the newspaper bearing such messages is in mass circulation, it is possible to explain why the emotional conditions of typical Russian citizens are the way they are.

The general increase in level of uneasiness during the system crisis is accompanied by the general decline of energy (shift of balance to the left, asthenic half-plane spaces of emotions).

Burning out, weariness from long-term uneasiness and fear during economic boom and wild capitalism cause sharp predominance of the opposite emotion - guilt.

In fig. 2 diagrams of an emotional spectrum of publications in "Rossiyskaya Gazeta" are shown - we can observe how it has been changing in the selected three months (from June to August) for the last four years. As we can see at the diagrams, the maximum disbalance in the ratio «fear - conscience » appeared in 2008. 


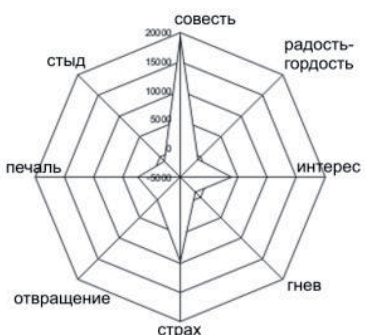

June 2007

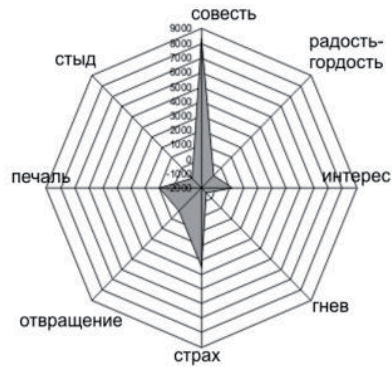

July 2007

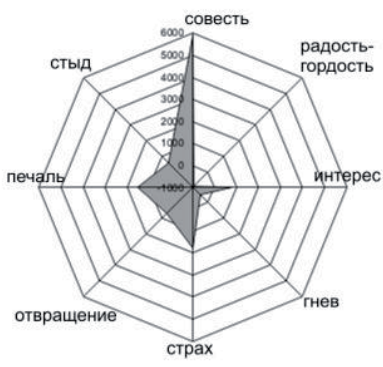

August 2007

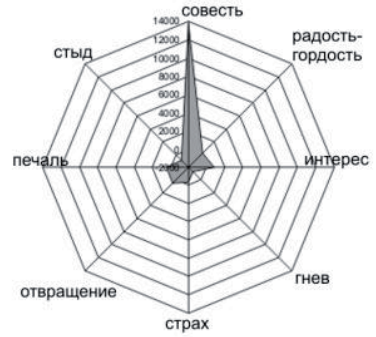

June 2008

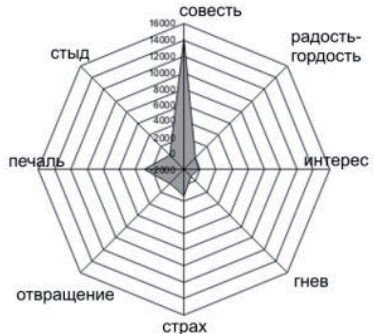

June 2009

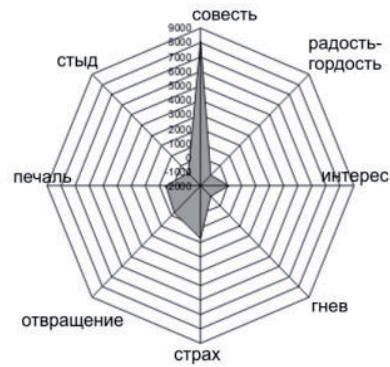

June 2010

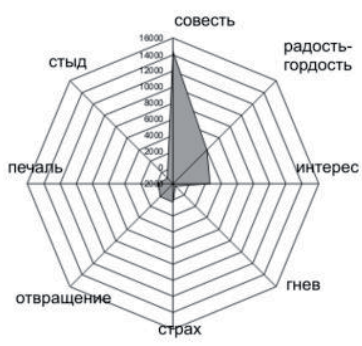

July 2008

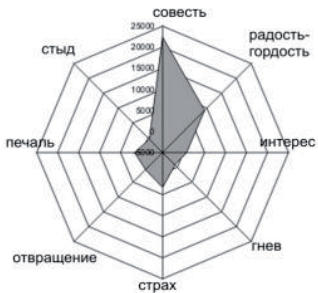

July 2009

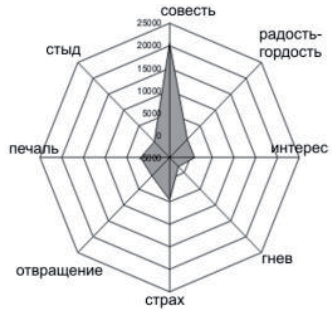

July 2010

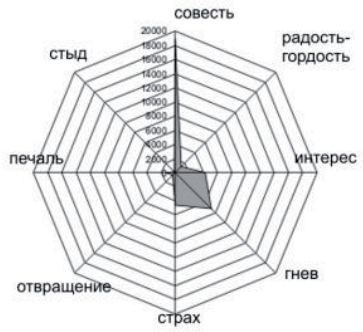

August 2008

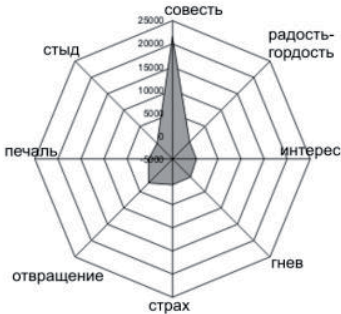

August 2009

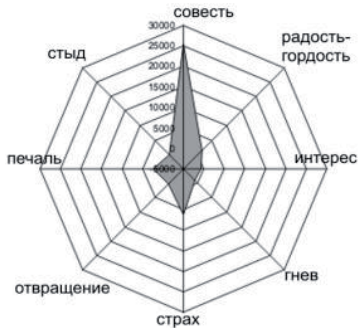

August 2010

Fig. 3. Diagrams of an emocional spectrum of publications in „Rossiyskaya Gazeta” 
Despite the general similarity of emotional spectra, the presence of various emotions in the texts published in "Rossiyskaya Gazeta" changes from a month by a month. In fig. 3 the dynamics of eight basic emotions for the investigated period is shown. The trend of the most expressed emotion - "conscience" - has tendency to increase.

It is possible to assume, that intensity of the given emotion continues to accrue with the feeling of guilt to extreme intensity of "repentance".

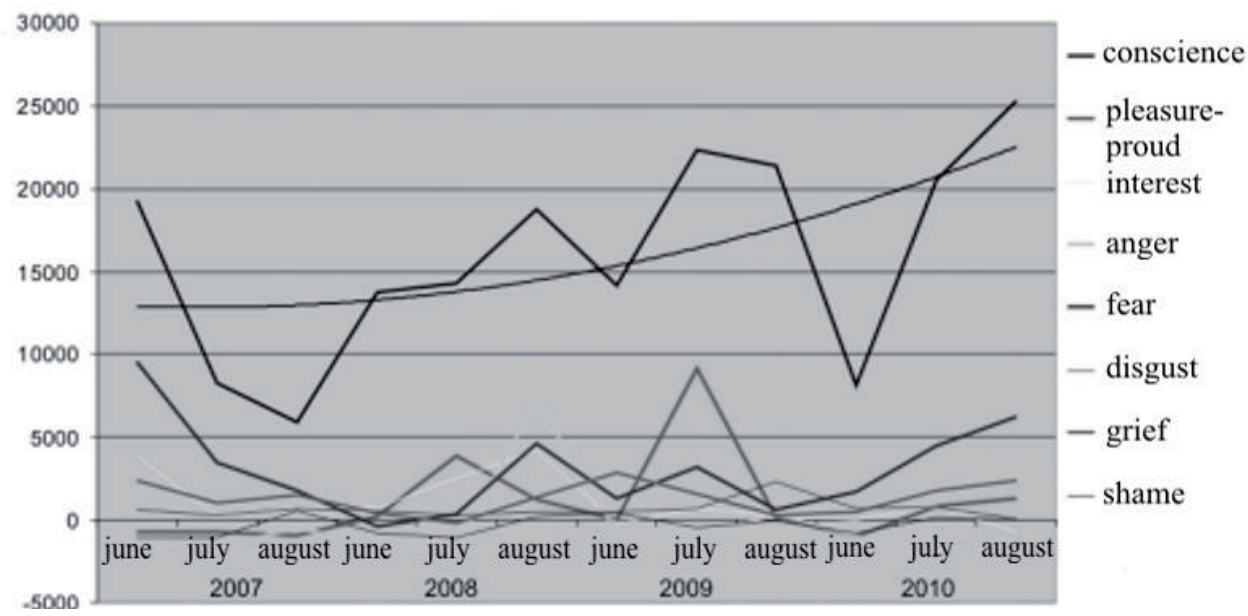

Fig. 3. The dynamics of presence of basic emotions in the texts published in "Rossiyskaya Gazeta" for the investigated period and polynomial trend of the second degree for emotion "conscience"

The following investigation phase became the correlation analysis of the received data file. In tab. 1 the factors of correlation in pairs of basic emotions are shown.

Tab. 1. Correlation factors between basic emotions in the texts published in "Rossiyskaya Gazeta"

\begin{tabular}{|l|c|c|c|c|c|c|c|}
\hline & $\begin{array}{c}\text { pleasure } \\
\text {-pride }\end{array}$ & interest & anger & fear & disgust & grief & shame \\
\hline conscience & 0,464576 & 0,107371 & 0,131072 & 0,437531 & 0,180303 & 0,308411 & 0,144548 \\
\hline $\begin{array}{l}\text { pleasure } \\
\text { pride }\end{array}$ & & 0,058752 & $-0,01293$ & $-0,06255$ & $-0,0994$ & $-0,0662$ & $-0,1037$ \\
\hline interest & & & 0,541846 & 0,397008 & $-0,10129$ & $-0,05327$ & $-0,20457$ \\
\hline anger & & & & 0,083503 & 0,075746 & $-0,01982$ & 0,364927 \\
\hline fear & & & & & $-0,27222$ & 0,635012 & $-0,06209$ \\
\hline disgust & & & & & & $-0,33259$ & 0,163182 \\
\hline grief & & & & & & & 0,461571 \\
\hline
\end{tabular}

Apparently, from the data presented in the table, the most significant correlation is present between emotions "fear" - "grief" and "interest" - "anger". It is possible to assume, that the journalists of "Rossiyskaya Gazeta" perceive, that there is an associative communication between these pairs of emotions. 
So, the communication between conditions of "fear" and "grief" suggests availability of a neurotic component in the image of the newspaper. Weakness, characteristic for a condition of grief, in this case is naturally connected with uneasiness and fear before the realities of life. It is quite clear, that the person feeling weak, is afraid of reality.

Correlation between "interest" and "anger" shapes an image of a mischievous, ironic condition of soul. The person with similar correlation, with curiosity and excitation, perceives the episodes sated by emotions of aggression and rage - criminal chronicles, descriptions of crimes, accidents and so forth.

The correlation in pair "conscience" - "pleasure-pride" is a little less meaningful. The given sheaf looks optimistic: it means, that display of duty, honour and conscience is perceived with pleasure and pride.

The correlation between emotion "fear" and emotions "conscience” and "interest” looks less healthy.

It is possible to assume, that the display of conscience continues to be perceived as a source of threat and causes disturbing experiences. At the same time experiences of danger (threat, uneasiness) are experienced with interest. The similar sheaf is characteristic for the gambling people inclined to risk and dangerous games.

The correlation "grief" - "shame" is specified with the absence of precise border between these adjacent emotions. The experience of shame (humility) is perceived as weakness. We shall notice, that the correlation between "grief" and "disgust" is negative.

These two adjacent emotions show antagonistic character - that is, experience of contempt, meanness, etc. does not make the person weak and sad.

As a whole the analysis of an emotional content of the texts in "Rossiyskaya Gazeta" reveals a controversial and complex image. On the one hand, for the given image the strong feeling of guilt and even repentance is characteristic, and these emotions are experienced with pleasure and pride.

On the other hand, the feeling of conscience is connected with fear and uneasiness which, in turn, are perceived with passion and gloating. The displays of modesty and shame are experienced as weakness and powerlessness (asthenia). Dominating emotion is thus of guilt, other emotions are expressed slightly.

The given image looks painfully enough. The powerful complex of guilt, with the background of deficiency of shame and propensity to hazardous risk, shapes an image unattractive and even pushing away. If it was a question of an image of an individual person it would be necessary to recognize such person as deeply problematic and neurotic.

It is difficult to expect, that the similar image plays a positive role in attracting tourists to Russia.

The image of Russia, which is shaped by the most popular Russian newspaper, was compared by us to that image which is shaped by the foreign mass-media writing about Russia. As the source of texts we used the popular Internet-resource «InoSMI».

The spectra of emotions received with analyzing the texts of this resource, are shown in picture 5. Apparently, on average the emotional spectrum of foreign publications about Russia looks absolutely different from a spectrum of "Rossiyskaya Gazeta”.

Foreign texts are more emotional and more symmetric, they are balanced on a parity of basic emotions that makes them similar to the spectra of works of the classical Russian literature. The emotion "conscience" is brightly expressed in a similar way to the texts in 
"Rossiyskaya Gazeta". This fact, however, may be treated as a reflection of features of mentality of the translators.

The essential difference from the Russian texts is a strong expressiveness of emotion "fear". In many cases this emotion is expressed as strongly as "conscience", and in all texts a high level of uneasiness is constantly present. The exceptionally high level of fear appropriating words "horror" and "panic" is registered in publications of 2007.

In further years the level of fear decreases to such degree which conforms to words "threat" and "uneasiness".

The distinctive feature of the emotional spectra of publications in InoSMI is also a higher level of presence of emotion "interest".

In some months the strong presence of emotions "anger" (down to a level "impudence", "hatred") and emotions "disgust" (up to a level "contempt", "meanness") is located.

As a whole, the emotional spectra of the texts in foreign mass-media look more healthy (less neurotic) and more varied, than the texts in "Rossiyskaya Gazeta".

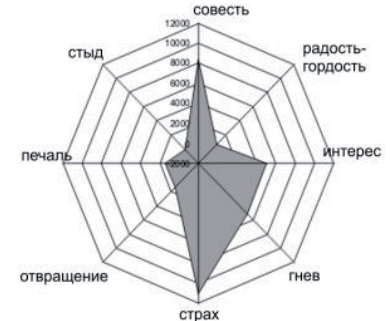

June 2007

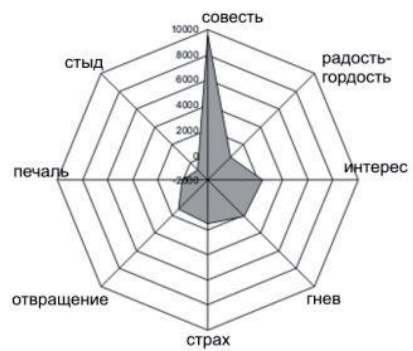

June 2008

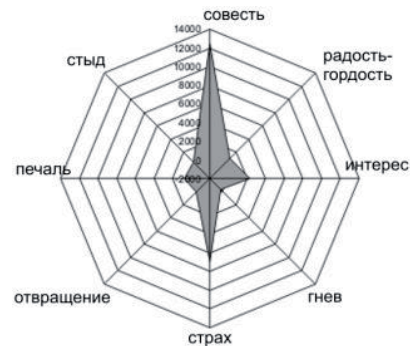

June 2009

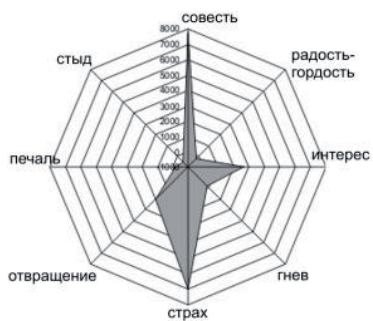

July 2007

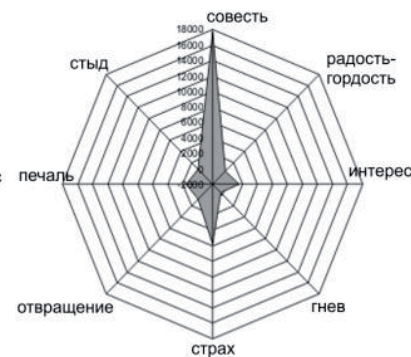

July 2008

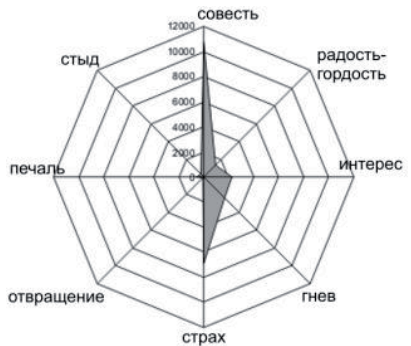

July 2009

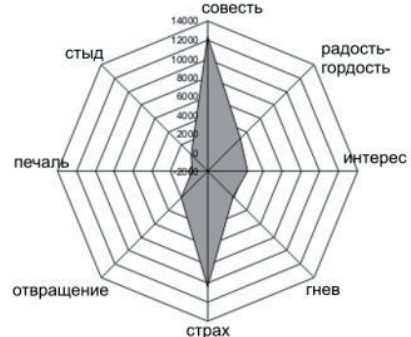

August 2007

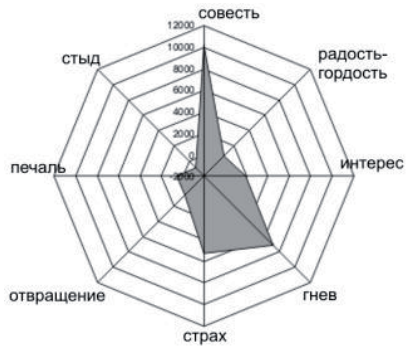

August 2008

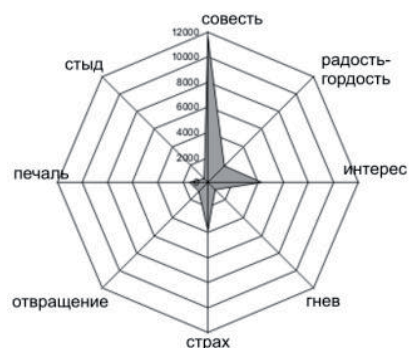

August 2009 


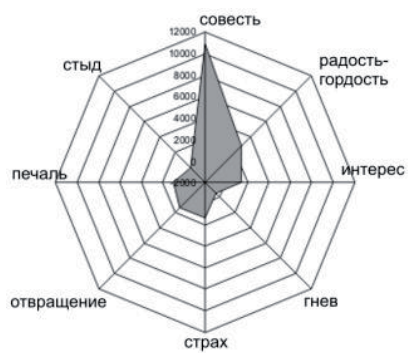

June 2010

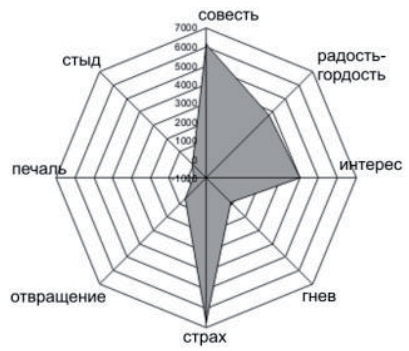

July 2010

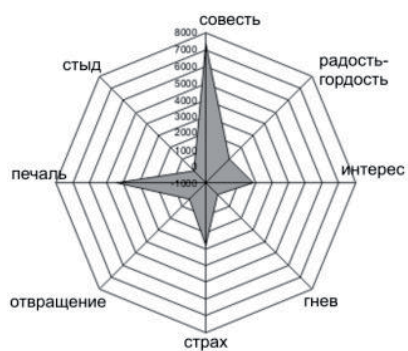

August 2010

Fig. 4. Diagrams the emotional spectra of publications in the texts in „Rossiyskaya Gazeta”

In fig. 5 the dynamics of presence of basic emotions in the texts published in InoSMI for the investigated period of time is shown. As we can see in the picture, an emotional spectrum of foreign publications is more balanced. Even if the emotion "conscience" is the leader in terms of the size of presence, it is still not with such big difference, as in the Russian massmedia.

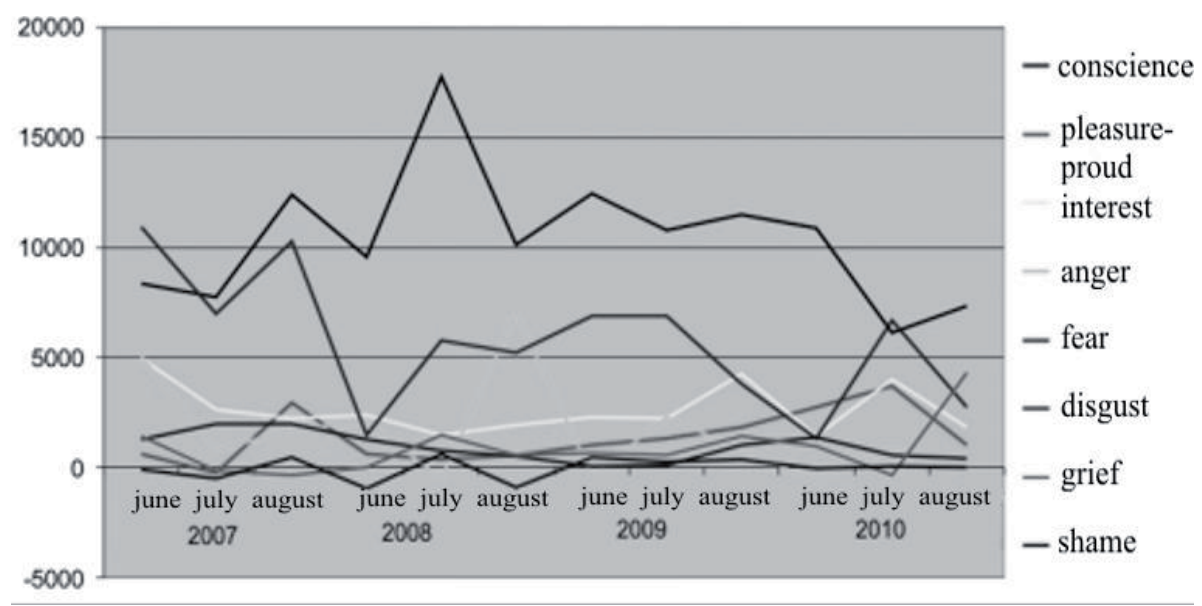

Fig. 5. The dynamics of basic emotions present in the texts of InoSMI in years 2007-2010

In fig. 6 the polynomial trends of three most often presented emotions for the investigated period of time are shown.

As we see in the picture, within two crisis years - 2008 and 2009 - the balance between emotions "conscience" and "fear" moved aside conscience, that is, aside greater orderliness and intelligence. At the same time the presence of emotion "interest" decreased. In 2010 the tendency has changed: the balance between order and chaos has started to move aside chaos, and the concern about Russia accrued. It is possible to assume, that in crisis years the fear in terms of Russia has conceded to the alarms caused by the internal economic problems of the Western world.

However, in the process of smoothing an acuteness of the experiences caused by the crisis, the habitual mistrust and fear in relation to Russia came back to a former level. 


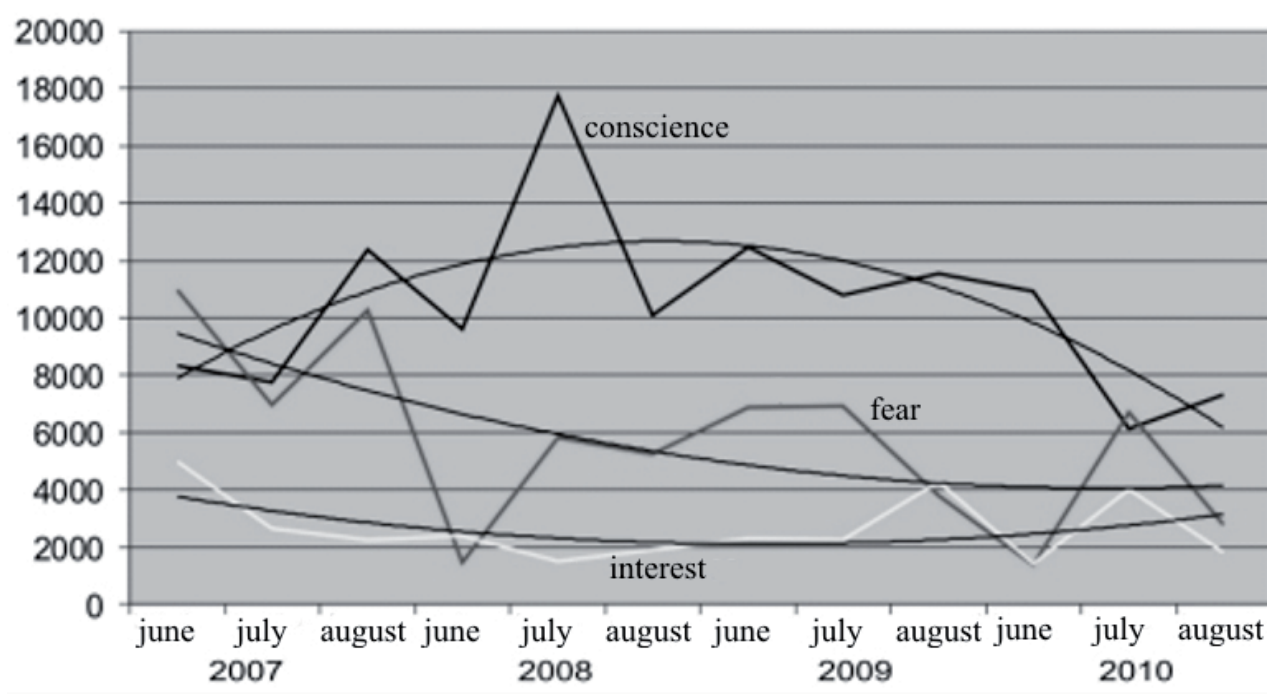

Fig 6. The trends of presence of three most commonly used emotions in years 2007-2010

In tab. 2 the correlations between the sizes of presence of basic emotions are shown.

Tab. 2. Correlation between the basic emotions in the texts published in InoSMI

\begin{tabular}{|l|l|l|l|l|l|l|l|}
\hline & conscience & $\begin{array}{c}\text { pleasure } \\
\text {-pride }\end{array}$ & interest & anger & fear & disgust & grief \\
\hline $\begin{array}{l}\text { pleasure } \\
\text {-pride }\end{array}$ & $-0,1472$ & & & & & & \\
\hline interest & $-0,42818$ & 0,14458 & & & & & \\
\hline anger & $-0,24756$ & $-0,24395$ & 0,284861 & & & & \\
\hline fear & 0,023553 & 0,023892 & 0,439288 & 0,337573 & & & \\
\hline disgust & $-0,07056$ & 0,026145 & 0,125578 & $-0,00029$ & 0,176007 & & \\
\hline grief & $-0,02274$ & $-0,23587$ & $-0,12299$ & $-0,18061$ & $-0,3192$ & $-0,35854$ & \\
\hline shame & 0,537318 & 0,354003 & 0,031965 & $-0,54938$ & 0,339745 & $-0,20941$ & 0,181299 \\
\hline
\end{tabular}

Apparently, as we see from the data in the table, the most meaningful correlation is observed between the emotions "shame" - "conscience" and "shame" - "anger". In both pairs the availability of correlation looks quite logical.

The emotions of shame and conscience adjoin in space of emotions and their positive correlation communication specifies the weak, dim border between them.

Differently given sheaf is possible to be designated as the «weakness in the face of the Order». A strong degree of conscience (guilt, repentance) forces the person to feel weak, non-dynamic. The given conclusion proves to be true in case of availability of negative correlation between conscience and pleasure-pride.

The negative factor of correlation between "shame" and "anger" is connected with the fact, that these emotions are opposite in space of emotions and they are natural antagonists. 
The experience of strong anger, and especially its burning out (accumulation of weariness with experience of emotion) stimulates healthy mentality to experiencing shame. On the contrary, the accumulation of weariness with experience of shame provokes the person to feelings of irritation, anger and impudence.

The relatives of absolute value, but opposite in sign correlations are observed in pairs "conscience" - "interest" and "interest" - "fear". The positive correlation between interest and fear, as well as in case of the analysis of texts in "Rossiyskaya Gazeta", specifies the tendency to passion, gloating and irony.

Apparently, foreign mass-media, in a similar way to Russian, follow the popular slogan: “Our news are your troubles".

The negative correlation between conscience and concern shows that foreign journalists and readers perceive the order as something deprived of interest.

On the contrary, everything that can cause interest, is the violation of order and law.

As a whole it is possible to notice, that a spectrum of emotions in the texts in foreign massmedia devoted to Russia, is less coherent and less neurotic. The image of our country, which is created in the texts of foreign journalists, looks a little scary, but causes obvious interest. The texts in foreign mass media are less neurotic than the texts of the Russian newspapers. However, in both of them, as well as in other, we can come across painful images.

These data show that the spatial distribution of plants producing emotions (especially the media) is not optimal. The emotions that fill the life of modern metropolis are of neurotic character. The global media uncontrollably reproduce and distribute these malicious images. As a result, the largest segment of the emotion market is saturated with the very dangerous and substandard goods.

\section{On the problem of spatial placement of the companies engaged in emotions}

There are whole areas of the modern market in which the emotional aspect of economic behavior initially plays a paramount role. These are the areas of manufacture and distribution of luxury goods, show-business and the so-called the market of cultural values - cinema, theatre, music and so on.

The emotions of pleasure, pride and interest are most demanded in the markets. However, not smaller demand exists for the emotions which can be perceived as negative - fear, uneasiness, gloating, anger.

The market of emotions is out of control in terms of harm that some emotions can cause to the consumer. The system of protection of consumer rights is not working in this market segment. As a result, "goods filled with emotions" can freely transmit pathogenic (neurotic) images.

The main type of enterprises that produce the emotions are the media. The spatial structure of location of such enterprises is poorly investigated. However, it is obvious that most of the emotional contented images are produced in large cities and metropolitan areas - megapolises and megalopolises. The images contain the emotions that are characteristic for the lifestyle of inhabitants living in a large and mega-urban agglomerations.

We have developed a special technique of frequency content analysis for measuring the emotional essence of the texts. The method is to measure the relative frequency of lemmas, signifying the emotions of different types and varying intensity. The emotional spectrum of some media outlets in years 2007 2010 were studied. The total input array was of about 250,000 words. 
The data shows that the spatial distribution of plants producing emotions (especially the media) is not optimal. The emotions that fill the life of modern metropolis are of neurotic character. The global media uncontrollably reproduce and distribute these malicious images. As a result, the largest segment of the emotion market is saturated with very dangerous and substandard goods.

$\mathrm{PhD}$, Konstantin L. Lidin

Irkutsk State Railway University, Russia

e-mail: lidinkl@hotmail.com

Mgr Maria E. Sumenkova, assistant professor Irkutsk State Railway University, Russia

e-mail: sibmarsha@rambler.ru 